\title{
Achtung Kostenfalle: Zahlungsverzug wird schärfer geahndet
}

\begin{abstract}
Von der Öffentlichkeit weitgehend unbeachtet ist im Juli 2014 ein Gesetz in Kraft getreten, das erhebliche Auswirkungen auf den Zahlungsverkehr im Geschäftsverkehr hat (Gesetz zur Bekämpfung von Zahlungsverzug im Geschäftsverkehr und zur Änderung des Erneuerbaren-Energien-Gesetzes). Wer nunmehr meint, dieses Gesetz würde inn nicht betreffen, da er Freiberufler ist und kein Gewerbetreibender, geht fehl.
\end{abstract}

Dr. jur. Gwendolyn Gemke // München

$\mathrm{D}$ as „Gesetz zur Bekämpfung von Zahlungsverzug im Geschäftsverkehr und zur Änderung des ErneuerbarenEnergien-Gesetzes" betrifft neben Kaufleuten im Sinne des Handelsgesetzbuches alle Unternehmer im Sinne des BGB - das heißt auch Freiberufler wie Ärzte, Steuerberater und Rechtsanwälte. Lediglich für Verbraucher gelten die verschärften Regelungen nicht. Es lohnt sich daher auch für den niedergelassenen Arzt, sich mit den Eckpunkten auseinanderzusetzen.

1. Verschärft wurden die Folgen des Zahlungsverzuges. Kommt der Unternehmer als Schuldner einer Geldforderung mit seiner Zahlung in Verzug, so betragen die gesetzlichen Verzugszinsen neuerdings 9 \%-Punkte über den jeweiligen Basiszinssatz. Voraussetzung ist, dass es sich um eine betriebliche Verbindlichkeit handelt.

2. Aber damit nicht genug: Der Gläubiger der Forderung - also zum Beispiel der Lieferant von Praxisbedarf oder aber der Vermieter - kann, wenn der Schuldner Unternehmer und nicht Verbraucher ist, zusätzlich zu den hohen Verzugszinsen eine Aufwandspauschale in Höhe von $40 €$ geltend machen, und dies unabhängig davon, ob ihm überhaupt oder aber in dieser Höhe ein Aufwand entstanden ist.

3. Darüber hinaus ist der Gläubiger berechtigt, ein Inkassounternehmen einzuschalten. Die Kosten des Forderungsinkassos kann er zusätzlich zu Verzugszins und Aufwandpauschale dem Schuldner in Rechnung stellen.
Unternehmer ist, wer bei Abschluss eines Rechtsgeschäftes in Ausübung seiner gewerblichen oder selbstständigen beruflichen Tätigkeit handelt. Erfasst sind damit beispielsweise sämtliche Bestellvorgänge im Zusammenhang mit der Führung einer Arztpraxis, Forderungen im Zusammenhang mit Handwerkerrechnungen oder aus dem Praxismietvertrag, aber auch aus der Beauftragung eines Steuerberaters mit der Erstellung des Jahresabschlusses einer Gemeinschaftspraxis.

In der eigenen Rechnungsstellung kann der Arzt in der Regel nicht von den verschärften Verzugsfolgen profitieren, denn Patienten sind Verbraucher im Sinne des BGB. Hier bleibt es bei den bisherigen Verzugsfolgen. Immerhin kann auch hier der Arzt steuern: Wird der Patient in der Rechnung besonders darauf hingewiesen, dass er als Schuldner spätestens in Verzug kommt, wenn er nicht innerhalb von 30 Tagen nach Fälligkeit und Zugang der Rechnung Zahlung leistet, kann der Arzt ohne weitere Mahnung nach Ablauf dieser Frist Verzugszinsen und Mahnkosten geltend machen.

Ziel des Gesetzgebers ist die Stärkung der Zahlungsmoral im Geschäftsverkehr. In der Praxis heißt es zukünftig, ein Augenmerk auf Eingangsrechnungen und das Zahlungsmanagement zu werfen. Nachlässigkeit in diesem Zusammenhang, das Liegenlassen oder Durchrutschen lassen betrieblicher Rechnungen kann teuer werden!
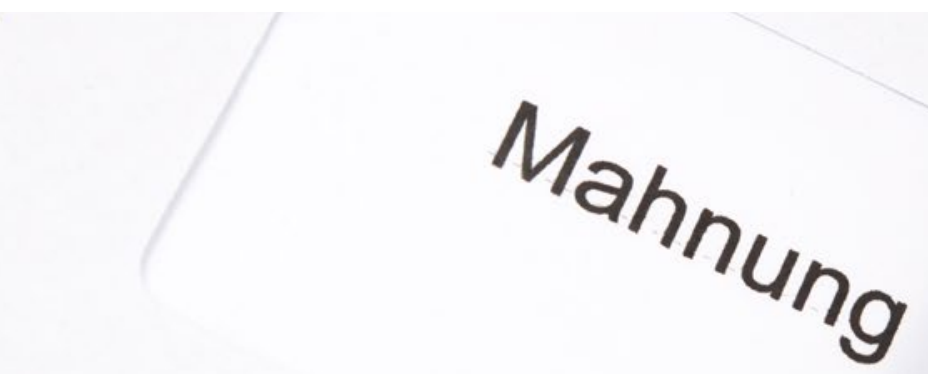